\title{
Balata ve Şim Bileşenlerinin Yarı Sıcak Preslenmesi ve Prosesler Sonrası Uygunluk Kontrolünün Sağlanması
}

\author{
Muhammed Abdullah Özel ${ }^{1 *}$, Cemil Sungur ${ }^{2}$ \\ 1*Elektrik Elektronik Mühendisliği / Lisansüstü Eğitim Enstitüsü, Konya Teknik Üniversitesi (ORCID: 0000-0003-3056-6438), ozel.muhammed@aydtr.com \\ ${ }^{2}$ Elektrik Elektronik Mühendisliği / Lisansüstü Eğitim Enstitüsü, Konya Teknik Üniversitesi (ORCID: 0000-0003-2340-6225), csungur@ktun.edu.tr
}

(2nd International Conference on Computer, Electrical and Electronic Sciences ICCEES 2021, September 1-3, 2021)

(DOI: 10.31590/ejosat.994120)

\begin{abstract}
ATIF/REFERENCE: Ozel, M., Sungur, C. (2021). Balata ve Şim Bileşenlerinin Yarı Sicak Preslenmesi ve Prosesler Sonrası Uygunluk Kontrolünün Sağlanması. Avrupa Bilim ve Teknoloji Dergisi, (30), 53-55.

$\ddot{O} \mathbf{z}$

Bir aracın hareket etmesi ne kadar önemliyse, durması da bir o kadar önemlidir. Fren sisteminin sağlıklı bir şekilde işlevini yerine getirmesi balatalarla doğrudan ilişkilidir. Balataların yapıları gereği ömürleri vardır. Bitmeye başlayan balata, kaliper ve disklerin sürtünmesine neden olur ve sürücülere ses olarak yansır. Ancak, frenden gelen sesin tek yanıtı balatanın bitmesi olmayabilir. Kaliper ve balata arasında oluşan orta frekanslı titreşimlerde bu sese neden olabilir. Bu sesin önlenmesi için ses önleyici sabitleyiciler gerekmektedir.

Balata gövdesine şim parçasının yapıştırılması için hali hazırda hazır yapıştırıcı ürünler kullanılmaktadır veya presleme işlemi kullanılmamaktadır. Üretim sırasında şim parçası balata üzerinde yanlış hizalanırsa ses ve titreşim sorunlarına sebebiyet verebilmektedir. Mevcut sistemlerde uygunluk ve pozisyon kontrolü tamamen operatör insiyatifindedir.

Bu nedenle yapılan çalışmada şim tabakasının yarı sıcak olarak fren balatası yüzeyine preslenmesi işlemi hassasiyetle gerçekleştirilip, işlem sonrasında, bu sistem için eğitilmiş derin öğrenme algoritmaları ile operatörden bağımsız olarak şim levhanın astar gövdesi üzerindeki konum kontrolü yapılabilmektedir. Şim bileşensiz balata, hazır yapıştırılmış şimli balata ve yarı-sıcak preslenmiş şimli balata karşılaştırılması yapılmış, yarı-sıcak preslenmiş ve doğru pozisyonlanmış şim bileşenli balatanın $300-5000 \mathrm{~Hz}$ frekans aralığındaki kaliperden gelen titreşimlerin $\% 80$ oranda engellediği belirlenmiştir.
\end{abstract}

Anahtar Kelimeler: Balata, Şim, Yarı Sıcak Pres, Görüntü İşleme, Kontrol.

\section{Semi-Hot Pressing with Brake Pad and Shim Components and Providing Control of Suitable after Proccess}

\begin{abstract}
As important as it is for a vehicle to move, it is just as important to stop. The healthy functioning of the brake system is directly related to the pads. Pads have a lifetime due to their structure. Running out of pads, causes friction of the caliper and discs and it is reflected to the drivers as sound. However, the only response to the noise from the brake may not be that the pad is worn out. The mid-frequency vibrations between the caliper and pad can cause noise on brake. Anti-noise stabilizers are required to prevent that noise.

Ready-made adhesive products are used to attach the shim piece to the pad body or pressing process is not used. On production process if shim attached to pad body misaligned way, it could cause noise and vibration. In existing production system, alignment on product is controlled by operator

Adhesion of the shim piece to the pad, which is one of the most important parts for vehicles, is already used with ready-made adhesive products or pressing is not used. If this component is misaligned, it can cause the same noise and vibration problems. In existing systems, product suitability and position control are completely under the operator's control.

For this reason, in the study, the process of pressing the shim layer to the brake pad surface in a semi-hot condition is carried out with precision, and after the process, the position control of the shim plate on the lining body of the shim plate can be performed independently of the operator with the deep learning algorithms trained for this system. A comparison was made between pad without shim component, ready glued shim pad and semi-hot pressed shim pad, and it was determined that the pad with semi-hot pressed and correctly positioned shim component prevented the vibrations coming from the caliper in the $300-5000 \mathrm{~Hz}$ frequency range by $80 \%$.
\end{abstract}

Keywords: Lining, Shim, Semi-Hot Press, Image Processing, Control

* Sorumlu Yazar: ozel.muhammed@aydtr.com 


\section{Giriş}

Çalışma kapsamında otomatik presleme operasyonu için literatür araştırması yapılarak proses kapsamında veriler toplanıp en uygun malzeme seçimi ve tasarım gerçekleştirilmesi için incelemeler yapılmıştır. Şim bileşeninin balata gövdesine eklenmesi, kaliperden oluşan seslerin engellenmesini sağlamaktadır. Kaliper ve balata arasında oluşan orta frekanslı titreşimlerin önlenmesi için ses önleyici sabitleyiciler (şim) gerekmektedir. $\mathrm{Bu}$ bileşen yanlış hizalanırsa da aynı sorunlara sebebiyet verebilmektedir. Literatür taraması geniş kapsamlı bir şekilde yapılmıştır. Halihazırda kullanılan sistemlerde şim bileşeni hazır yapışkanlı bir şekilde balata gövdesine yapıştırılmakta veya şim takılmadan üretilmektedir. Literatür taraması sonucunda bu prosesin yarı sıcak presleme işlemi ile yapılmadığı ve proses sonrası şim hizalama kontrolünün yapılmadığı görülmüştür. Tasarım için hem presleme hem de kontrol prosesi göz önüne alınmış, buna yönelik makine tasarımı Solidworks ile yapılmıştır.

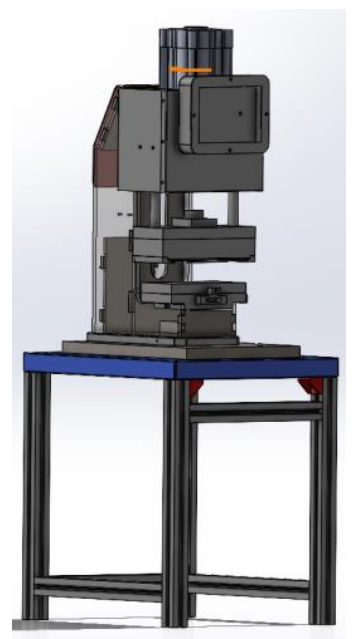

Şekil 1. Makine Tasarımı

\section{Materyal ve Metot}

\subsection{Sistem}

Sistemde kontrolcü olarak PLC kullanılmıştır. Sicaklık dengelemesi için PID kontrol yazılımı sisteme uygun bir şekilde yazılmıştır. Sicaklık dengelemesi için PID kontrolü önem taşımaktadır. Hassas yük kontrolü gerçekleştirilebilmesi için yük hücresi kullanılmıştır ve sistemde istenilen yükün kontrol edilebilmesi için oransal regülatör kullanılmıştır. Operatör tararfından yük, sıcaklık ve işlem süresi verileri SCADA üzerinden girilebilecek, ürün ağacına göre kalıplaşmış reçete sistemi hazırlanabilecek ve güncellenebilecektir. Panelden girilen yük, loadcell tarafından algılandığ 1 andan itibaren istenilen işlem süresi boyunca presleme işlemi gerçekleştirilecektir. Proses sonrası görüntü işleme ve derin öğrenme algoritmaları kullanılarak gerçeleştirilecek olan presleme işlemi, şim parcasının uygun kriterde prosesini tamamladığını tespit edecektir.

\subsubsection{Yarl-Sıcak Press \& Görüntü İşleme}

Şim sacı, balata gövdesi üzerine $240 \mathrm{C}^{\circ}$ yarı sıcak presleme işlemi ile yapılmaktadır. AYD AR-GE merkezinde yapılan çalışmalar ile $240 \mathrm{C}^{\circ}$ sıcaklık değeri, şim sacının balata yüzeyine preslendikten sonra yapılan kopma testleri sonucunda belirlenmiştir. Yapışma işlemi sırasında önemli kriterlerden biri de preslemede süresidir. Presleme süresi, şim sacının mekanik özelliklerini etkileyecektir.

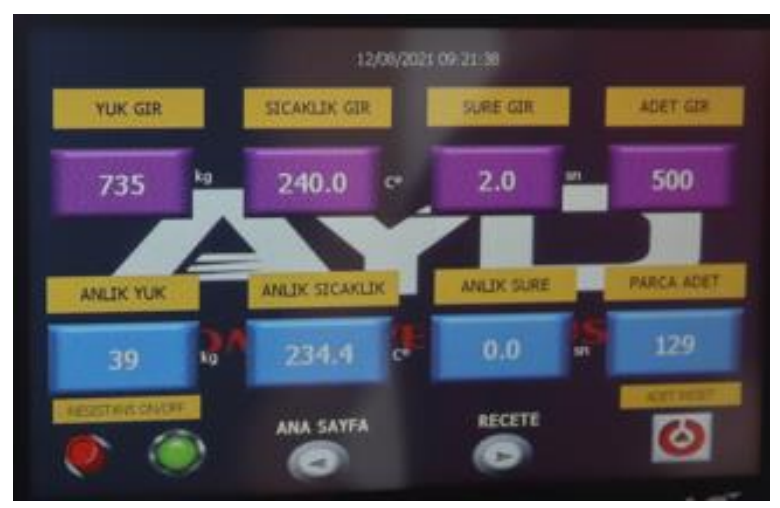

Şekil 2. SCADA Panel Görüntüsü

$300-5000 \mathrm{~Hz}$ frekans aralığında olan titreşimlerin ve gıcırdamaların en önemli nedeni ses önleyici sabitleyicilerin yani şimlerin yanlış hizalanmasından kaynaklanmaktadır. Bu sebeple yarı sicak presleme prosesi sonrası şimlerin pozisyon kontrolleri tam otomatik bir şekilde yapılmalıdır. Hazırlanan görüntü işleme algoritması ile balata üzerinde şim sınır noktaları belirlenmektedir. Şim sınır noktaları presleme sonrası uygunluk kontrolü için belirlenen bölgeye konulmalıdır. Sınır noktaları için belirlenen yüzdelik altında kalırsa red verilir ve kırmızı uyarı 1şı̆̆ yanar, istenilen yüzdelikte olursa onay verilir.

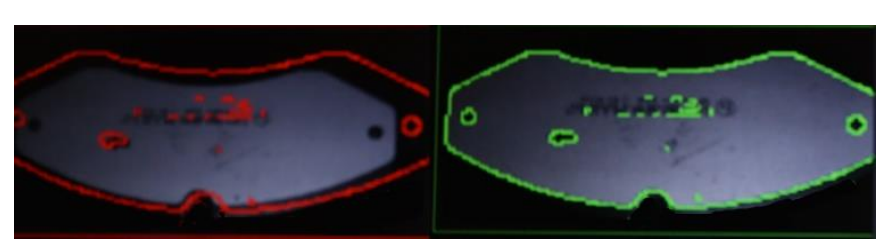

Şekil 3. Örnek Onay/Red Görüntüsü

Balata üzerinde şim var olup olmadığı Derin öğrenme algoritması ile belirlenir. Derin öğrenme algoritması olarak YOLO algoritması tercih edilmiştir.

YOLO tüm görüntüyü tek bir örnekte alır ve bu kutular için sinırlayıcı kutu koordinatlarını ve sinıf olasılıklarını tahmin eder. YOLO kullanmanın en büyük avantajı üstün hızıdır ve saniyede 45 kare işleyebilir. Şim yoksa tespit işlemi gerçekleşmez.

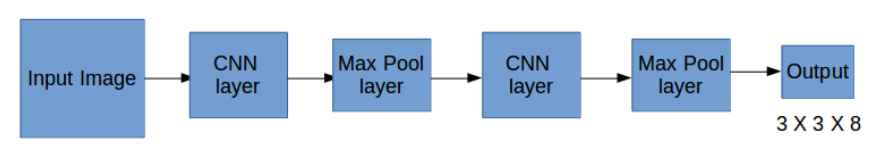

$100 \times 100 \times 3$

Şekil 4. YOLO İş Aklşı 


\section{Araştırma Sonuçları ve Tartışma}

\subsection{Bulgular}

Yapılan çalışma ile balata gövdesi üzerine şim parçası $\% 100$ yük kontrollü olarak preslenmiştir. Yarı sıcak şekilde preslenen şim parçasının yapışma oranının yapılan çekme testlerinin sonucunda uygun olduğu tespit edilimiştir. Presleme operasyonu sonrasında şim parçasının balata gövdesi üzerine uygun formda konumlandırılması için görüntü işleme tekniği kullanılmış ve Python programlama dilinden yararlanılarak proses kontrol süreci \%100 başarı sağlanmıştır. Hatalı ürün sonrası yapılan tespit ile operatör kontrolüne bakılmaksızın görüntü işleme algoritmasından gelen bilgi PLC ile haberleşerek sistemin belirlenen şim presleme prosedürünün kontrolünü sağlamaktadır.

\section{Sonuç}

$\mathrm{Bu}$ prosesle ilgili yapılan literatür araştırmalarında şim sacının balata gövdesi üzerindeki konumunun ve yapışma oranının, balatalar üzerindeki sönümleme davranışına etkisi araştırılmış, sonrasında sönümleme ve gürültüler test edilerek sönümleme oranları test edilmiştir. Araştırmalar sonucunda literatürde karşılaşılan konum ve yapışkanlık oranından kaynaklanan birçok soruna, bu çalışmaya entegre edilen kontrolcü ve algılayıcılar vasıtasıyla çözüm sağlanmış ve şim malzemesinin balata üzerinde verimli bir şekilde çalışabilmesi için önemli bir metot geliştirilmiş̧ir.

Yapılan çalışmada sıcaklık ve yük verisinin sürekli olarak kontrol altında tutulması için PID kontrol yöntemi kullanılmıştır. Yük hücresi kullanılmış ve yarı sıcak presleme prosesi otomatikleştirilmiştir. Bu geliştirmenin sonucunda şim sacının balata gövdesi üzerindeki yapışkanlık oranı arttırılmıştır. Presleme süreci sonrası balata üzerine şim parçasının montajı görüntü işleme algoritmaları ile kontrol edilerek gerçekleştirilmiştir ve şim sacının balata gövdesi üzerindeki pozisyonlama hatasından dolayı oluşabilecek gürültü problemleri önlenmiştir. Geliştirmeler sonucunda araç frenleme sisteminin en önemli parçası olan balata için sönümleme ve fren sesi kalitesi iyileștirilmiştir. Prosesin yük, sıcaklık ve konum verileri sistem tarafından sürekli kontrol edilmesi ve literatürde bulunan mevcut sistemlere göre otomatik çalıșması faktörleri nedeniyle bu çalışma, şim sacı ve balata bileşenlerinin yarı sıcak preslenmesi prosesi için en uygun sistem olarak değerlendirilebilir.

\section{Teşekkür}

$\mathrm{Bu}$ çalışma AYD0121-06 nolu proje ile desteklenmiştir. Çalışmada desteklerinden dolayı Danışman hocamız Sn. Prof. Dr. Cemil SUNGUR'a ve AYD AR-GE müdürümüz Sn. Ahmet ÇAKAL'a teşekkür ederiz.

\section{Kaynakça}

[1] Pulkit Sharma, "Practical Guide to Object Detection using the Popular YOLO Framework Part3", December. 6, 2018.

[2] Sugözü, İ., Mutlu, İ., \& Öner, C. (2011). Fren Balatas1 Üretiminde Sicak Presleme Süresinin Frenleme Karakteristiğine Etkisinin Araştırılması. In 6th International Advanced Technologies Symposium (IATS'11), Elazığ, Turkey.
[3] Ertan, R. (2008). Fren balata malzemelerinin optimizasyonu ve üretim parametrelerinin analizi.

[4] Topuz, P. (2018). Otomobil disk fren balatalarının deneysel yöntemlerle karakterizasyonu ve karşılaştırılması. Marmara Fen Bilimleri Dergisi, 30(3), 241-248.

[5] Schmid, D., Gräbner, N., \& von Wagner, U. (2017). Experimental investigations of brake pad shim properties. PAMM, 17(1),41-44.

[6] Schmid, D., Gräbner, N., \& von Wagner, U. (2019). On Brake Pad Shim Characterization: a Homogenization Approach and Finite Element Analysis. In New Achievements in Continuum Mechanics and Thermodynamics (pp. 447-464). Springer, Cham. 